\title{
Peramalan Jumlah Penduduk Kabupaten Semarang dengan Metode Box-Jenkins
}

\author{
Emma Novita Sari ${ }^{1, a)}$, Tundjung Mahatma ${ }^{1, b)}$ \\ ${ }^{1}$ Program Studi Matematika, Fakultas Sains dan Matematika, Universitas Kristen Satya Wacana, \\ Jl. Diponegoro 52-60, Kota Salatiga 50711, Jawa Tengah, Indonesia. \\ E-mail: ${ }^{a}$ 662017012@student.uksw.edu, ${ }^{\text {b) tundjung.mahatma@uksw.edu }}$
}

\begin{abstract}
Forecasting is a science or technique to estimate a value in the future using reference data in the past and current data. Forecasting the population of Semarang Regency is very necessary because population data are often used as the basis for planning or development targets in the future. The purpose of this study was to determine the results of forecasting the population of Semarang Regency in 2020-2025 using the Box-Jenkins method. The data used is the population data of Semarang Regency in 1989 - 2019. This data can be modeled with the Autoregressive Integrated Moving Average (ARIMA) model. After being analyzed, the best model obtained is the $\operatorname{ARIMA}(2,1,1)$ model. The results of forecasting the population of Semarang Regency for 2020 to 2025 are 1,064,529 people, 1,075,971 people, 1,086,606 people, 1,097,182 people, $1,107,346$ people, and 1,117,284 people.
\end{abstract}

Keywords: Box-Jenkins, Forecasting, Time Series, Total Population.

\begin{abstract}
Abstrak
Peramalan merupakan ilmu atau teknik untuk menduga suatu nilai pada waktu yang akan datang menggunakan referensi data di masa lalu dan data saat ini. Peramalan jumlah penduduk Kabupaten Semarang sangat diperlukan karena data jumlah penduduk sering dijadikan sebagai dasar untuk perencanaan maupun sasaran pembangunan di waktu yang akan datang. Tujuan dari penelitian ini adalah untuk mengetahui hasil peramalan jumlah penduduk Kabupaten Semarang tahun 2020 - 2025 dengan metode Box-Jenkins. Data yang digunakan adalah data jumlah penduduk Kabupaten Semarang tahun 1989 - 2019. Data tersebut dapat dimodelkan dengan model Autoregressive Integrated Moving Average (ARIMA). Setelah dianalisis, model terbaik yang didapatkan adalah model ARIMA(2,1,1). Hasil peramalan jumlah penduduk Kabupaten Semarang untuk tahun 2020 sampai dengan 2025 berturut-turut sebesar 1.064.529 jiwa, 1.075.971 jiwa, 1.086.606 jiwa, 1.097.182 jiwa, 1.107.346 jiwa, dan 1.117.284 jiwa.
\end{abstract}

Kata-kata kunci: Box-Jenkins, Jumlah Penduduk, Peramalan, Runtun Waktu. 


\section{PENDAHULUAN}

Indonesia adalah negara dengan jumlah penduduk yang sangat banyak (Welianto, 2020). Indonesia menempati peringkat keempat negara dengan penduduk paling banyak di dunia setelah Tiongkok, India, dan Amerika Serikat (Saputro, 2016). Jawa Tengah merupakan provinsi ketiga dengan jumlah penduduk terbesar di Indonesia setelah Jawa Barat dan Jawa Timur (Iqbal, 2019). Kabupaten Semarang adalah salah satu kabupaten dari 35 kabupaten/kota di provinsi Jawa Tengah. Berdasarkan data proyeksi penduduk, jumlah penduduk di Kabupaten Semarang tahun 2019 sebanyak 1.053.786 jiwa (BPS, 2020).

Berkurang atau bertambahnya jumlah penduduk di suatu daerah berperan penting bagi daerah itu sendiri karena data jumlah penduduk dapat dijadikan sebagai penunjang dalam perencanaan pembangunan (Putra, 2017). Selain itu, data jumlah penduduk juga dibutuhkan di bidang ekonomi, pendidikan, kesehatan, dan sebagainya (Putra, 2017).

Peramalan jumlah penduduk Kabupaten Semarang sangat diperlukan karena data jumlah penduduk sering dijadikan sebagai dasar untuk perencanaan maupun sasaran pembangunan di waktu yang akan datang (Aswad, 2013). Peramalan merupakan ilmu atau teknik untuk menduga suatu nilai pada waktu yang akan datang menggunakan referensi data di masa lalu dan data saat ini. Biasanya, peramalan melibatkan analisis runtun waktu. Analisis runtun waktu merupakan prosedur analisis yang digunakan untuk mengetahui pergerakan nilai suatu variabel sebagai akibat dari perubahan waktu. Analisis runtun waktu diterapkan untuk menduga nilai variabel pada suatu waktu tertentu di masa yang akan datang. Salah satu metode yang dapat digunakan dalam menentukan model pada runtun waktu adalah metode Box-Jenkins. Berdasarkan Bowerman dan Richard (1993) yang dikutip oleh Hermawan (2011) menyebutkan bahwa metode Box-Jenkins adalah metode yang paling populer dan sering digunakan dalam peramalan data runtun waktu.

Berdasarkan latar belakang di atas, perumusan masalah pada penelitian ini adalah "Bagaimana hasil peramalan jumlah penduduk Kabupaten Semarang tahun 2020 - 2025 menggunakan metode Box-Jenkins?". Tujuan dari penelitian ini adalah untuk mengetahui hasil peramalan jumlah penduduk Kabupaten Semarang tahun 2020 - 2025 berdasarkan data jumlah penduduk Kabupaten Semarang tahun 1989 - 2019. Hasil penelitian diharapkan dapat memberi gambaran kepada Pemerintah Kabupaten Semarang tentang pertambahan jumlah penduduk sehingga dapat dijadikan sebagai dasar dalam pengambilan suatu keputusan untuk meningkatkan kualitas hidup penduduk (Ruslan, 2016).

\section{METODOLOGI}

\section{Data}

Data yang digunakan dalam penelitian ini adalah data sekunder yang berupa data runtun waktu jumlah penduduk Kabupaten Semarang tahun 1989 - 2019. Data tersebut diperoleh dari situs resmi Badan Pusat Statistik (BPS) Kabupaten Semarang. TABEL 1 menunjukkan jumlah penduduk Kabupaten Semarang tahun 1989 - 2019.

TABEL 1. Jumlah penduduk Kabupaten Semarang tahun 1989 - 2019.

\begin{tabular}{cccccc}
\hline Tahun & $\begin{array}{c}\text { Jumlah } \\
\text { Penduduk }\end{array}$ & Tahun & $\begin{array}{c}\text { Jumlah } \\
\text { Penduduk }\end{array}$ & Tahun & $\begin{array}{c}\text { Jumlah } \\
\text { Penduduk }\end{array}$ \\
\hline 1989 & 766.209 & 2000 & 831.262 & 2011 & 946.708 \\
1990 & 772.513 & 2001 & 835.022 & 2012 & 960.497 \\
1991 & 779.826 & 2002 & 871.137 & 2013 & 974.115 \\
1992 & 788.974 & 2003 & 844.869 & 2014 & 987.597 \\
1993 & 755.044 & 2004 & 891.951 & 2015 & 1.000 .887 \\
1994 & 763.427 & 2005 & 896.048 & 2016 & 1.014 .198 \\
1995 & 770.935 & 2006 & 899.549 & 2017 & 1.027 .489 \\
1996 & 777.490 & 2007 & 906.112 & 2018 & 1.040 .629 \\
1997 & 780.656 & 2008 & 913.022 & 2019 & 1.053 .786 \\
1998 & 785.097 & 2009 & 917.745 & & \\
1999 & 788.149 & 2010 & 932.702 & & \\
\hline
\end{tabular}




\section{Metode Penelitian}

Langkah-langkah pemodelan menggunakan metode Box-Jenkins secara umum terdiri dari empat langkah berikut (Rosadi, 2018).

\section{Preprocessing Data dan Identifikasi Model Stasioner}

Data yang akan diolah dengan metode Box-Jenkins harus memenuhi syarat stasioner dalam varian dan rata-rata (Hermawan, 2011). Pada tahap ini, dilakukan pemeriksaan kestasioneran pada data. Identifikasi dapat dilakukan dengan melihat plot awal dari data runtun waktu. Untuk mengetahui kestasioneran dalam rata-rata, dapat dilakukan menggunakan uji formal, yaitu uji akar unit (Nugraha, 2017). Pada penelitian ini, uji akar unit yang digunakan adalah uji Kwiatkowski-Philips-Schmidt-Shin (KPSS). Preprocessing data seperti transformasi Box-Cox atau differencing juga dilakukan apabila data yang digunakan belum stasioner. Jika data sudah stasioner, dapat ditentukan model yang tepat untuk menggambarkan sifat-sifat data. Model runtun waktu pada metode Box-Jenkins di antaranya adalah

\section{a. Autoregressive (AR)}

Secara umum, model AR orde ke-p $(A R(p))$ dirumuskan sebagai berikut (Laura, 2019).

$$
X_{t}=\phi_{1} X_{t-1}+\phi_{2} X_{t-2}+\cdots+\phi_{p} X_{t-p}+e_{t}
$$

di mana $X_{t}$ adalah data aktual pada saat $t ; X_{t-i}$ adalah data aktual pada saat $t-i, i=$ $1,2, \ldots, p ; \phi_{i}$ adalah parameter AR ke- $i, i=1,2, \ldots, p$; dan $e_{t}$ adalah nilai kesalahan pada saat $t$.

Model $\operatorname{AR}(p)$ dapat juga ditulis menggunakan operator backward shift seperti berikut (Desvina and Desmita, 2015).

$$
\begin{gathered}
X_{t}-\phi_{1} X_{t-1}-\phi_{2} X_{t-2}-\cdots-\phi_{p} X_{t-p}=e_{t} \\
X_{t}-\phi_{1} B X_{t}-\phi_{2} B^{2} X_{t}-\cdots-\phi_{p} B^{p} X_{t}=e_{t} \\
\left(1-\phi_{1} B-\phi_{2} B^{2}-\cdots-\phi_{p} B^{p}\right) X_{t}=e_{t} \\
\phi(B) X_{t}=e_{t}
\end{gathered}
$$

\section{b. Moving Average (MA)}

Secara umum, model MA orde ke- $q(M A(q))$ dirumuskan sebagai berikut (Laura, 2019).

$$
X_{t}=e_{t}-\theta_{1} e_{t-1}-\theta_{2} e_{t-2}-\cdots-\theta_{q} e_{t-q}
$$

di mana $X_{t}$ adalah data aktual pada saat $t ; \theta_{j}$ adalah parameter MA ke-j, $j=1,2, \ldots, q$; $e_{t}$ adalah nilai kesalahan pada saat $t ; e_{t-j}$ adalah nilai kesalahan pada saat $t-j, j=$ $1,2, \ldots, q$.

Model MA $(q)$ dapat juga ditulis menggunakan operator backward shift seperti berikut (Desvina and Desmita, 2015).

$$
\begin{gathered}
X_{t}=e_{t}-\theta_{1} e_{t-1}-\theta_{2} e_{t-2}-\cdots-\theta_{q} e_{t-q} \\
X_{t}=e_{t}-\theta_{1} B e_{t}-\theta_{2} B^{2} e_{t}-\cdots-\theta_{q} B^{q} e_{t} \\
X_{t}=\left(1-\theta_{1} B-\theta_{2} B^{2}-\cdots-\theta_{q} B^{q}\right) \\
X_{t}=\theta(B) e_{t}
\end{gathered}
$$

c. Autoregressive Moving Average (ARMA)

Model $\operatorname{ARMA}(p, q)$ dirumuskan sebagai berikut (Laura, 2019).

$$
X_{t}=\phi_{1} X_{t-1}+\phi_{2} X_{t-2}+\cdots+\phi_{p} X_{t-p}+e_{t}-\theta_{1} e_{t-1}-\theta_{2} e_{t-2} \cdots-\theta_{q} e_{t-q}
$$


dimana $X_{t}$ adalah data aktual pada saat $t ; X_{t-i}$ adalah data aktual pada saat $t-i, i=$ $1,2, \ldots, p ; \phi_{i}$ adalah parameter AR ke- $i, i=1,2, \ldots, p ; e_{t}$ adalah nilai kesalahan pada saat $t ; e_{t-j}$ adalah nilai kesalahan pada saat $t-j, j=1,2, \ldots, q ; \theta_{j}$ adalah parameter MA ke- $j, j=1,2, \ldots, q$.

Model $\operatorname{ARMA}(p, q)$ dapat juga ditulis menggunakan operator backward shift seperti berikut (Laura, 2019).

$$
\begin{gathered}
X_{t}-\phi_{1} X_{t-1}-\phi_{2} X_{t-2}-\cdots-\phi_{p} X_{t-p}=e_{t}-\theta_{1} e_{t-1}-\theta_{2} e_{t-2} \cdots-\theta_{q} e_{t-q} \\
X_{t}-\phi_{1} B X_{t}-\phi_{2} B^{2} X_{t} \cdots-\phi_{p} B^{p} X_{t}=e_{t}-\theta_{1} B e_{t}-\theta_{2} B^{2} e_{t-2}-\cdots-\theta_{q} e_{t-q} \\
\left(1-\phi_{1} B-\phi_{2} B^{2}-\cdots-\phi_{p} B^{p}\right) X_{t}=\left(1-\theta_{1} B-\theta_{2} B^{2}-\cdots-\theta_{q} B^{q}\right) e_{t} \\
\phi(B) X_{t}=\theta(B) e_{t}
\end{gathered}
$$

\section{d. Autoregressive Integrated Moving Average (ARIMA)}

Jika data runtun waktu tidak stasioner maka model umum $\operatorname{ARIMA}(p, d, q)$ terpenuhi. Notasi $p$ menunjukkan orde dari proses AR, notasi $d$ menunjukkan banyaknya differencing yang dilakukan untuk membuat data menjadi stasioner, dan notasi $q$ menunjukkan orde dari proses MA (Safitri, 2016).

Secara umum, model ARIMA $(p, d, q)$ dirumuskan sebagai berikut (Perdana, 2017).

$$
\phi(B)(1-B)^{d} X_{t}=\theta(B) e_{t}
$$

di mana $\phi(B)=\left(1-\phi_{1} B-\phi_{2} B^{2}-\cdots-\phi_{p} B^{p}\right) ; \theta(B)=\left(1-\theta_{1} B-\theta_{2} B^{2}-\cdots-\right.$ $\left.\theta_{q} B^{q}\right) ; \phi_{i}$ adalah parameter AR ke- $i, i=1,2, \ldots p ; B$ adalah operator mundur; $d$ adalah banyaknya differencing; $X_{t}$ adalah data aktual pada saat $t ; \theta_{j}$ adalah parameter MA ke- $j, j=1,2, \ldots, q ; e_{t}$ adalah nilai kesalahan pada saat $t$.

Penentuan model dilakukan dengan cara memperhatikan plot ACF dan PACF. Overfitting juga dapat dilakukan dalam pemodelan dengan cara menganalisis model runtun waktu yang memiliki orde lebih tinggi dari model yang telah didapatkan (Rosadi, 2018).

\section{Estimasi Parameter dari Model}

Setelah mendapatkan model yang mungkin sesuai untuk data, langkah selanjutnya adalah melakukan estimasi terhadap parameter dalam model. Langkah ini dilakukan dengan bantuan software $\mathrm{R}$ 4.0.3. Pada tahap ini, nilai koefisien pada masing-masing model yang diduga menjadi model terbaik akan diuji signifikansinya. Jika terdapat koefisien dari model yang tidak signifikan, model tersebut dibuang (Samsiah, 2008).

\section{Uji Diagnostik dan Pemilihan Model Terbaik}

Uji diagnostik dilakukan pada model yang memenuhi uji signifikansi parameter. Uji ini bertujuan untuk mengetahui apakah model yang diusulkan sudah layak digunakan untuk peramalan atau belum. Terdapat 2 jenis uji pada tahap ini, yaitu:

\section{a. Uji Residual White Noise}

Untuk mengetahui apakah residual bersifat acak atau tidak, dapat dilakukan uji autokorelasi residual menggunakan uji Ljung-Box.

b. Uji Residual berdistribusi Normal

Uji residual berdistribusi normal dapat dilakukan menggunakan uji KolmogorovSmirnov. 
Apabila terdapat beberapa model yang memenuhi uji diagnostik di atas, maka pemilihan model terbaik dapat dilakukan dengan memperhatikan nilai AIC (Akaike's Information Criterion) yang didefinisikan sebagai berikut (Safitri, 2016).

$$
\operatorname{AIC}(M)=-2 \ln [\text { maximum likelihood }]+2 M
$$

dimana $M$ menunjukkan parameter pada model. Model terbaik adalah model dengan AIC terkecil (Laura, 2019).

\section{Peramalan dengan Model Terbaik}

Setelah model terbaik diperoleh, model tersebut dapat digunakan untuk peramalan.

\section{HASIL DAN PEMBAHASAN}

\section{Preprocessing Data dan Identifikasi Model Stasioner}

GAMBAR 1 adalah plot data asli jumlah penduduk Kabupaten Semarang tahun 1989 - 2019.

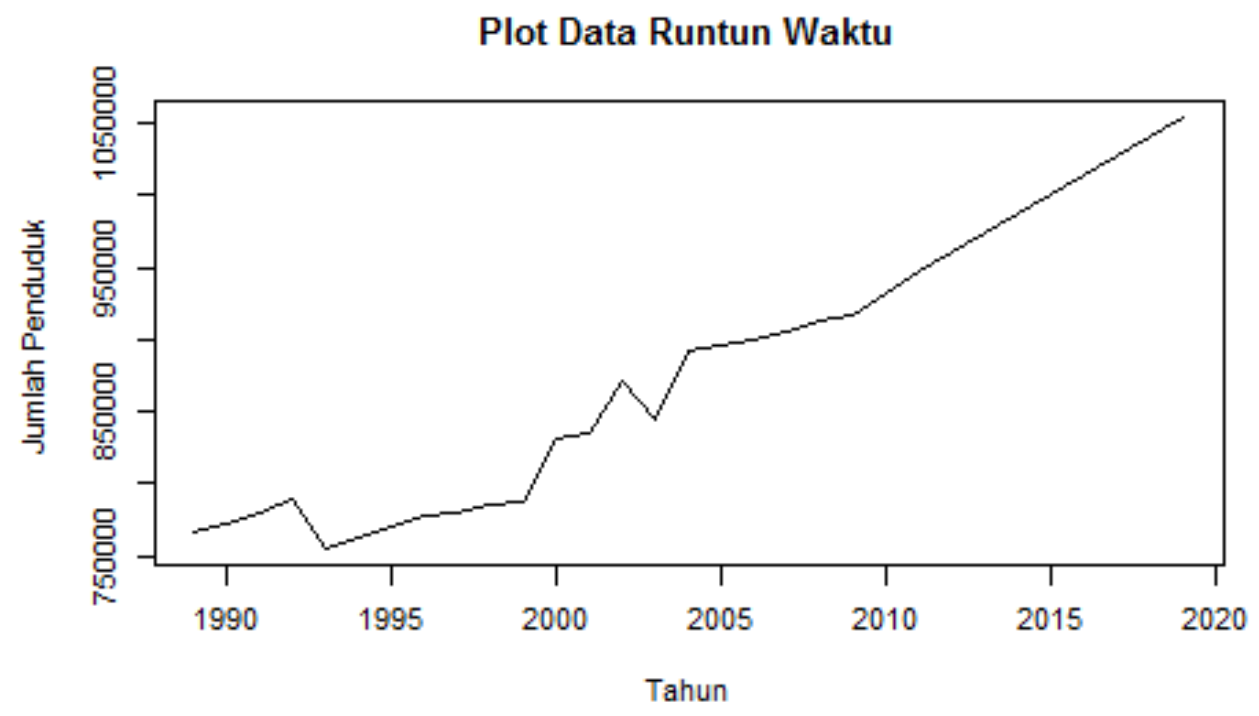

GAMBAR 1. Plot data runtun waktu jumlah penduduk Kabupaten Semarang tahun 1989 - 2019.

Berdasarkan GAMBAR 1, data terlihat tidak stasioner karena mengandung unsur tren, yang selanjutnya akan dikonfirmasikan menggunakan uji akar unit dengan uji KPSS. Hasil dari uji KPSS adalah sebagai berikut:

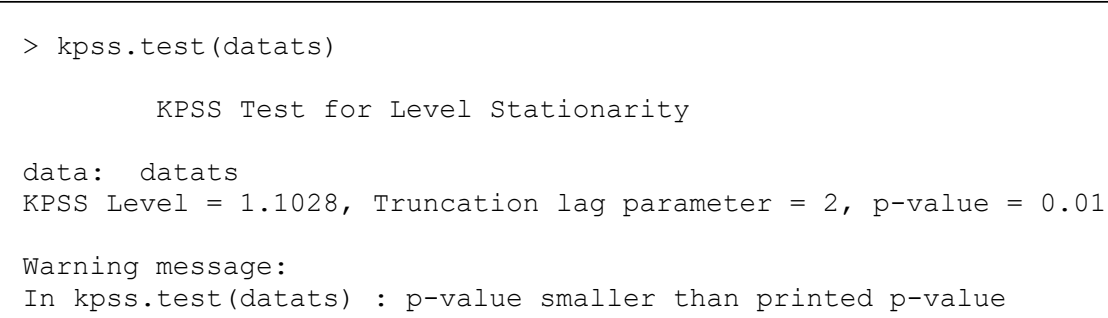

Nilai p-value hasil uji adalah 0,01 . Nilai tersebut lebih kecil dari $\alpha=0,05$ sehingga uji KPSS menunjukkan bahwa hipotesis nol yang artinya terdapat akar unit dalam data (data tidak stasioner) diterima. Untuk itu, perlu dilakukan differencing pada data sampai data tersebut stasioner. Setelah 
dilakukan differencing, kemudian dilakukan uji KPSS kembali. Hasil dari uji KPSS adalah sebagai berikut:

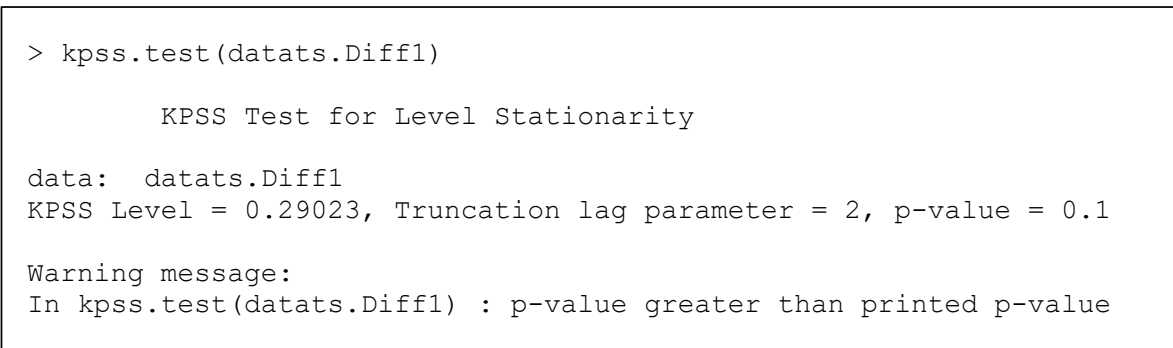

Nilai $p$-value hasil uji adalah 0,1 . Nilai tersebut lebih besar dari $\alpha=0,05$ sehingga uji KPSS menunjukkan bahwa hipotesis nol yang artinya terdapat akar unit dalam data (data tidak stasioner) ditolak.

Setelah mendapatkan data yang stasioner, dapat ditentukan bentuk model yang kira-kira sesuai untuk data. Peramalan ini menggunakan model Autoregressive Integrated Moving Average (ARIMA). Untuk mengidentifikasi model ARIMA yang tepat, digunakan plot ACF dan PACF data hasil differencing.

Plot ACF

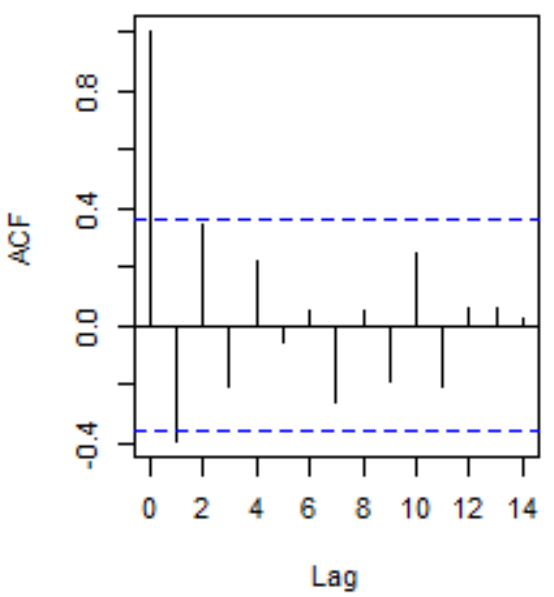

Plot PACF

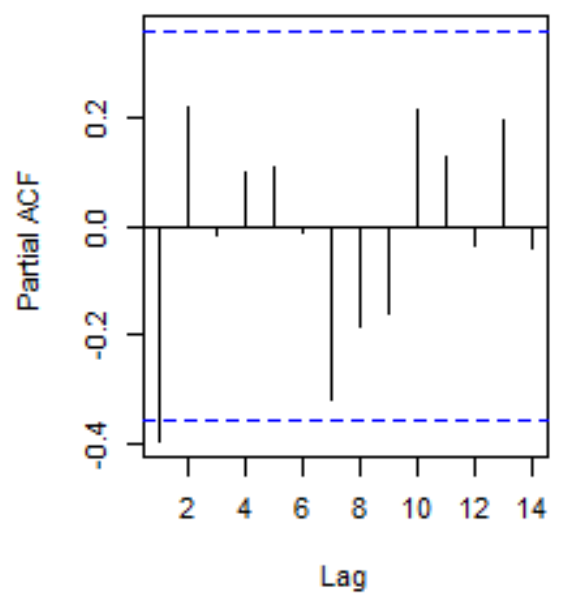

GAMBAR 2. Plot ACF dan PACF data hasil differencing.

GAMBAR 2 menunjukkan plot ACF dan PACF terpotong setelah lag-1 yang berarti orde MA yaitu $q=1$ dan AR yaitu $p=1$. Dengan sebelumnya dilakukan differencing satu kali $(d=1)$, diperoleh model ARIMA $(1,1,1)$.

Overfitting terhadap model dapat dilakukan dengan menambahkan satu orde pada setiap parameter yang terdapat pada model utama. Dalam hal ini, dipilih model $\operatorname{ARIMA}(2,1,1)$ dan $\operatorname{ARIMA}(1,1,2)$.

\section{Estimasi Parameter dari Model}

Langkah selanjutnya adalah melakukan estimasi terhadap parameter dari model dan menguji signifikansi parameternya. TABEL 2 menunjukkan hasil estimasi dan uji signifikansi parameter. 
TABEL 2. Hasil estimasi dan uji signifikansi parameter.

\begin{tabular}{cccccc}
\hline \multirow{2}{*}{ Model } & \multicolumn{2}{c}{ Parameter } & \multirow{2}{*}{ SE } & sign. & \multirow{2}{*}{ Signifikansi } \\
\hline \multirow{2}{*}{ ARIMA(1,1,1) } & AR(1) & 0,9949 & 0,0238 & 0 & $\checkmark$ \\
& MA(1) & $-0,9408$ & 0,1342 & 0 & $\checkmark$ \\
\hline \multirow{2}{*}{ ARIMA(2,1,1) } & AR(1) & 0,4836 & 0,1965 & 0,0198 & $\checkmark$ \\
& AR(2) & 0,4749 & 0,1680 & 0,0083 & $\checkmark$ \\
& MA(1) & $-0,7526$ & 0,2019 & 0,0008 & $\checkmark$ \\
\multirow{2}{*}{ ARIMA(1,1,2) } & AR(1) & 0,8142 & 0,1073 & 0,0000 & $\checkmark$ \\
& MA(1) & $-1,3903$ & 0,5049 & 0,0099 & $\checkmark$ \\
& MA(2) & 0,9965 & 0,7185 & 0,1757 & $\times$ \\
\hline
\end{tabular}

Berdasarkan Tabel 2, dapat dilihat bahwa model $\operatorname{ARIMA}(1,1,1)$ dan $\operatorname{ARIMA}(2,1,1)$ memiliki nilai sign. lebih kecil dari $\alpha=0,05$ untuk semua parameternya. Sedangkan model ARIMA $(1,1,2)$ tidak memenuhi uji signifikansi parameter sehingga model tersebut dibuang.

\section{Uji Diagnostik dan Pemilihan Model Terbaik}

Uji diagnostik dilakukan dengan menggunakan uji Ljung-Box dan Kolmogorov-Smirnov. TABEL 3 menunjukkan hasil uji diagnostik dari model $\operatorname{ARIMA}(1,1,1)$ dan $\operatorname{ARIMA}(2,1,1)$. Nilai $\alpha$ yang digunakan adalah 0,05 .

TABEL 3. Hasil uji diagnostik.

\begin{tabular}{ccc}
\hline \multirow{2}{*}{ Model } & \multicolumn{2}{c}{$p$-value } \\
\cline { 2 - 3 } & White Noise & Distribusi Normal \\
\hline ARIMA $(1,1,1)$ & 0,08355 & 0,01648 \\
ARIMA $(2,1,1)$ & 0,6547 & 0,16 \\
\hline
\end{tabular}

Berdasarkan TABEL 3, dapat dilihat bahwa model ARIMA(1,1,1) memenuhi uji residual White Noise karena memiliki nilai $\mathrm{p}$-value $>\alpha$ dan tidak memenuhi uji residual berdistribusi normal karena memiliki nilai $\mathrm{p}$-value $<\alpha$. Sedangkan model $\operatorname{ARIMA}(2,1,1)$ memnuhi uji residual White Noise dan berdistribusi normal karena memiliki nilai p-value $>\alpha$ sehingga model $\operatorname{ARIMA}(2,1,1)$ dapat digunakan untuk peramalan.

\section{Peramalan dengan Model Terbaik}

Setelah memperoleh model terbaik, dapat diprediksi jumlah penduduk Kabupaten Semarang beberapa periode ke depan (dalam hal ini, diambil 6 periode ke depan). Persamaan untuk model $\operatorname{ARIMA}(2,1,1)$ adalah sebagai berikut.

$$
\begin{gathered}
\phi(B)(1-B)^{d} X_{t}=\theta(B) e_{t} \\
\left(1-\phi_{1} B-\phi_{2} B^{2}\right)(1-B) X_{t}=\left(1-\theta_{1} B\right) e_{t} \\
\left(1-B-\phi_{1} B+\phi_{1} B^{2}-\phi_{2} B^{2}+\phi_{2} B^{3}\right) X_{t}=\left(1-\theta_{1} B\right) e_{t} \\
X_{t}-B X_{t}-\phi_{1} B X_{t}+\phi_{1} B^{2} X_{t}-\phi_{2} B^{2} X_{t}+\phi_{2} B^{3} X_{t}=e_{t}-\theta_{1} B e_{t} \\
X_{t}-X_{t-1}-\phi_{1} X_{t-1}+\phi_{1} X_{t-2}-\phi_{2} X_{t-2}+\phi_{2} X_{t-3}=e_{t}-\theta_{1} e_{t-1} \\
X_{t}=X_{t-1}+\phi_{1} X_{t-1}-\phi_{1} X_{t-2}+\phi_{2} X_{t-2}-\phi_{2} X_{t-3}+e_{t}-\theta_{1} e_{t-1}
\end{gathered}
$$

TABEL 4 menunjukkan hasil peramalan menggunakan model $\operatorname{ARIMA}(2,1,1)$. 
TABEL 4. Hasil peramalan jumlah penduduk Kabupaten Semarang 6 periode ke depan.

\begin{tabular}{cc}
\hline Tahun & Jumlah Penduduk \\
\hline 2020 & 1.064 .529 \\
2021 & 1.075 .971 \\
2022 & 1.086 .606 \\
2023 & 1.097 .182 \\
2024 & 1.107 .346 \\
2025 & 1.117 .284 \\
\hline
\end{tabular}

Hasil peramalan tersebut juga dapat dinyatakan dalam plot seperti pada GAMBAR 3.

\section{Plot Hasil Peramalan}

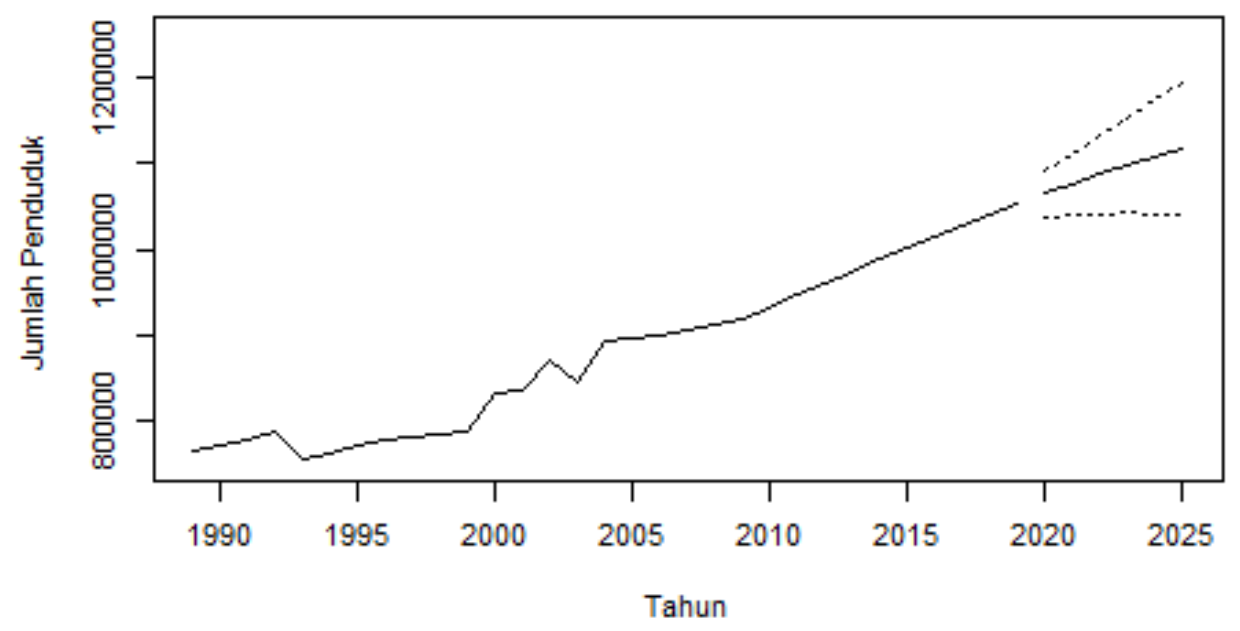

GAMBAR 3. Plot hasil peramalan jumlah penduduk Kabupaten Semarang 6 periode ke depan.

\section{KESIMPULAN}

Dari hasil analisis data yang telah dilakukan, dapat disimpulkan bahwa model terbaik untuk data jumlah penduduk Kabupaten Semarang adalah $\operatorname{ARIMA}(2,1,1)$ dengan persamaan sebagai berikut.

$$
X_{t}=X_{t-1}+\phi_{1} X_{t-1}-\phi_{1} X_{t-2}+\phi_{2} X_{t-2}-\phi_{2} X_{t-3}+e_{t}-\theta_{1} e_{t-1}
$$

Hasil peramalan jumlah penduduk Kabupaten Semarang untuk tahun 2020 sampai dengan 2025 berturut-turut sebesar 1.064.529 jiwa, 1.075.971 jiwa, 1.086.606 jiwa, 1.097.182 jiwa, 1.107.346 jiwa, dan 1.117.284 jiwa.

\section{UCAPAN TERIMA KASIH}

Terima kasih kepada Program Studi (Prodi) Matematika Universitas Kristen Satya Wacana (UKSW), Badan Pusat Statistik (BPS) Kaupaten Semarang, dan semua pihak yang telah membantu dalam penelitian ini. 


\section{REFERENSI}

Aswad, M. H. (2013) 'Analisis Peramalan Jumlah Penduduk Kota Palopo Tahun 2013-2017', AlKhwarizmi Jurnal Pendidikan Matematika dan Ilmu Pengetahuan Alam, 1(1), pp. 49-58. doi: https://doi.org/10.24256/jpmipa.v1i1.83.

BPS (2020) Kabupaten Semarang dalam Angka 2020. BPS: Kabupaten Semarang.

Desvina, A. P. and Desmita, E. (2015) 'Penerapan Metode Box-Jenkins dalam Meramalkan Indeks Harga Konsumen di Kota Pekanbaru', Jurnal Sains Matematika dan Statistika, 1(1), pp. 39-47.

Hermawan, E. (2011) 'Perbandingan Metode Box-Jenkins dan Holt-Winters dalam Prediksi Anomali OLR Pentad di Kawasan Barat Indonesia', Jurnal Sains Dirgantara, 9(1), pp. 25-35.

Iqbal, R. (2019) Provinsi di Indonesia yang Paling Banyak Penduduknya, IDN Times.

Laura, V. (2019) Peramalan Banyaknya Penabung di Credit Union Sumber Kasih Teraju dengan Metode Box-Jenkins. Universitas Sanata Dharma.

Nugraha, D. (2017) 'Ketersediaan Jagung berdasarkan Peramalan Produksi dan Produktivitasnya di Tengah Persaingan Penggunaan Lahan di Indonesia', in Prosiding Seminar Nasional Agroinovasi Spesifik Lokasi Untuk Ketahanan Pangan Pada Era Masyarakat Ekonomi ASEAN, pp. 447-454.

Perdana, A. A. R. (2017) Penerapan Metode ARIMA untuk Peramalan Suplai Suku Cadang Kendaraan Bermotor. Universitas Sanata Dharma.

Putra, N. A. (2017) Prediksi Jumlah Penduduk menggunakan Fuzzy Time Series Model Chen (Studi Kasus: Kota Tanjungpinang). Universitas Maritim Raja Ali Haji.

Rosadi, D. (2018) Analisis Runtun Waktu dan Aplikasinya dengan R. Gadjah Mada University Press.

Ruslan, M. (2016) 'Prediksi Jumlah Penduduk Provinsi Kalimantan Selatan Menggunakan Metode Semi Average', IJSE - Indonesian Journal on Software Engineering, 2(1), pp. 1-7. doi: https://doi.org/10.31294/ijse.v2i1.601.

Safitri, T. (2016) Perbandingan Peramalan menggunakan Metode Exponential Smoothing HoltWinters dan ARIMA. Universitas Negeri Semarang.

Samsiah, D. N. (2008) Analisis Data Runtun Waktu menggunakan Model ARIMA (p,d,q) (Aplikasi: Data Pendapatan Pajak Kendaraan Bermotor di Propinsi Daerah Istimewa Yogyakarta. UIN Sunan Kalijaga.

Saputro, A. B. (2016) Peramalan Pertumbuhan Penduduk per Kecamatan di Kabupaten Kediri menggunakan Metode Kuadrat Terkecil. Universitas Nusantara Persatuan Guru Republik Indonesia.

Welianto, A. (2020) Permasalahan Kependudukan di Indonesia, Kompas. Available at: https://www.kompas.com/skola/read/2020/07/08/174500069/permasalahan-kependudukan-diindonesia?page=all (Accessed: 19 December 2020). 